This item was submitted to Loughborough's Research Repository by the author.

Items in Figshare are protected by copyright, with all rights reserved, unless otherwise indicated.

\title{
Running the penultimate lap of the race: a multi-method analysis of growth, generativity, career orientation and personality amongst men in mid/late career
}

\section{PLEASE CITE THE PUBLISHED VERSION}

http://dx.doi.org/10.1111/joop.12125

\section{PUBLISHER}

Wiley / @ The British Psychological Society

\section{VERSION}

AM (Accepted Manuscript)

\section{PUBLISHER STATEMENT}

This work is made available according to the conditions of the Creative Commons Attribution-NonCommercialNoDerivatives 4.0 International (CC BY-NC-ND 4.0) licence. Full details of this licence are available at: https://creativecommons.org/licenses/by-nc-nd/4.0/

\section{LICENCE}

CC BY-NC-ND 4.0

\section{REPOSITORY RECORD}

Arnold, John, and Michael G. Clark. 2015. "Running the Penultimate Lap of the Race: A Multi-method Analysis of Growth, Generativity, Career Orientation and Personality Amongst Men in Mid/late Career". Loughborough University. https://hdl.handle.net/2134/18384. 
MEN IN MID/LATE CAREER

Running head: MEN IN MID/LATE CAREER

Running the Penultimate Lap of the Race: A Multi-Method Analysis of Growth, Generativity, Career Orientation and Personality amongst Men in Mid/Late Career

\author{
John Arnold \\ Loughborough University \\ Mike Clark \\ University of the West of England
}

\begin{abstract}
Author Note
John Arnold, School of Business and Economics, Loughborough University, United Kingdom. Mike Clark, Centre for Employment Studies Research, Bristol Business School, University of the West of England, Bristol, United Kingdom.
\end{abstract}

Author order is alphabetical. The authors contributed equally to this article.

The article is dedicated to the memory of Denise Clark (d.2012). 
MEN IN MID-LATE CAREER

\begin{abstract}
The dynamics of development in mid/late career are relatively uncharted territory in empirical research, and represent a point of intersection between work/organizational psychology and life-span developmental psychology. Using multi-method data from a study of 41 men aged between 45 and 55, we investigated the correlates and compatibility of two key developmental phenomena at this career stage: personal growth and generativity. We found that a forward momentum career orientation (not necessarily in the form of hierarchical advancement) was positively associated with generativity and personal growth, whereas a preoccupation with career maintenance had strong negative relationships with both. However, men's orientation toward their career did not uniquely predict generativity or growth when these variables were also regressed on the personality traits of ego resiliency and ego development, suggesting that personality more than subjective career stage is the root of a positive experience of mid/late career. We also conclude that the importance of personal growth is not confined to the first half of career, and that contributing to others (i.e. generativity) is compatible with the ostensibly self-focused concerns of growth. Differences between findings from self-report questionnaire and coded interview narratives suggest that method matters in the investigation of these constructs.
\end{abstract}

Keywords: Mid-career, late career, career stage, personality, career orientation, personal growth, generativity, ego development, ego-resiliency, workplace 
MEN IN MID-LATE CAREER

\section{Practitioner Points}

Personal growth is relevant to many people in mid-late career. Therefore it is important not to assume that people at this stage are content to "coast” towards retirement.

Generativity - a desire to contribute to current and future generations - is also important for many workers in mid-late career. It can be expressed in various ways, and is not confined to the stereotypical mentoring role. Organizations should therefore facilitate and reward older workers’ generative contributions to mainstream activities.

A sense of forward momentum in career is associated with growth and generativity. In contrast, a maintenance career orientation (i.e. holding on to prior gains) is associated with less positive results. Discerning a person's career orientation is therefore a quick route to knowing whether they are likely to seek challenges and contribute to the well-being and development of others at this career stage.

Relatively stable personality attributes appear to lie behind both career orientation and growth and generativity in mid-late career. Therefore it may be difficult to achieve change in the way people approach this part of their career. 


\section{Running the Penultimate Lap of the Race:}

\section{A Multi-Method Analysis of Growth, Generativity, Career Orientation and Personality amongst Men in Mid-Late Career}

Research suggests that in mid/late career many people still want to feel that they are 'getting somewhere’ (Hall \& Rabinowitz, 1988). A feeling of forward momentum is often central to people’s vitality and commitment to their work (Kooij, de Lange, Jansen \& Dikkers, 2013). In mid/late career, formal advancement in an organizational or occupational hierarchy is less available, and less soughtafter even by the most ambitious (Howard \& Bray, 1988; Warr, Miles \& Platts, 2001). Fortunately, however, 'getting somewhere' can be understood in other ways. In this paper we investigate two pathways along which career can advance when promotion no longer matters, or is blocked. One entails personal growth. If individuals seek out new challenges, master new tasks, and learn new things, then the growth that results can offer a sense of progress. A second route forward concerns ways in which individuals can continue to advance their substantive contribution to their organization and to society through what Erikson (1963) called 'generativity' - the desire to establish and guide future generations. This is a central preoccupation of middle age.

Demographic trends towards an older population, and intense financial pressures on pension schemes, mean that many people will continue working longer than they anticipated (Magnus, 2008). Therefore, rather than thinking of people aged around 50 as static or even starting their 'final descent' into retirement, it is important to understand the dynamics of this period of career (Clark \& Arnold, 2008) both from the point of view of organizations seeking to harness an aging workforce (Truxillo, Cadiz, Rineer, Zaniboni \& Fraccaroli, 2012) and individuals seeking to make the most of extended working lives (Weigl, Müller, Hornung, Zacher \& Angerer, 2013). In this article we therefore integrate career and life-span development theory to explore the correlates and interplay of growth and 
MEN IN MID-LATE CAREER

generativity amongst men in mid/late career, using multiple methods and measures to access these two constructs.

Since relatively little is known about psychological variables which may dispose individuals towards personal growth and generativity in the context of career, our first general aim is to examine whether growth and generativity are associated with two career orientations (forward momentum and maintenance, Super et al., 1995), and with two personality constructs derived from life-span developmental psychology but not previously examined in a career context: ego resiliency (Block, 1982) and ego development (Loevinger, 1976). Second, we ask whether career orientation explains additional variance in growth and generativity over and above personality. Our third aim is to test conflicting theoretical predictions about whether or not growth and generativity are compatible at this stage of career. Can the focus on self implied by personal growth and the focus on others implied by generativity co-exist, or are they mutually exclusive?

\section{Growth and Generativity}

Personal growth concerns differentiation and integration of self in pursuit of fulfilment or personal wholeness (Bauer \& McAdams, 2004). It occurs in the process of engaging creatively with challenges which require people to use their capacities and develop additional ones (Alderfer, 1972).

Desire for growth is generally considered a relatively stable attribute of personality (e.g. Maslow, 1970; Rogers, 1961). Across all walks of life, many studies suggest some decline with age (Kooij, De Lange, Jansen, Kanfer \& Dikkers, 2011). However, in Ryff's (1989) study of US adults, although men’s scores for personal growth fell between early and late adulthood, they nevertheless peaked in middle age. Demiray and Bluck (2014) found no difference between young and middle-aged adults in self-reported personal growth scores, which were well above the midpoint of their scale. There are grounds, therefore, for believing that personal growth remains a salient concern of mid-life. However, empirical evidence concerning personal growth in the context of mid/late career is scarce. 
MEN IN MID-LATE CAREER

Generativity was defined by Erikson (1959) as the central developmental accomplishment of mature adulthood, with concern for establishing and guiding the next generation as its proto-typical form. Recent research in work psychology (Kooij et al., 2013, Kooij \& van de Voorde, 2011; Zacher, Rosing, Henning \& Frese, 2011; Zacher, Schmitt \& Gielnik, 2012) confirms that this form of generativity increases with age, and links it to leadership effectiveness (Zacher et al., 2011), and effective succession in family firms (Zacher et al., 2012). However, for Erikson and many more recent theorists (e.g. McAdams \& de St Aubin, 1992; Peterson \& Stewart, 1993), generativity also encompasses a wider range of concerns and behaviours aimed at ensuring that the world is a congenial habitat for the species. These include care directed towards contemporaries and elders, as well as the young. They can be expressed in impersonal (e.g. political) as well as interpersonal forms (Erikson, Erikson \& Kivnick, 1986). We draw on this broader generativity construct in the present study.

Erikson (1959) proposed that the central developmental significance of generativity lies in the transition from youthful self-preoccupation to care for what is 'other'. This 'other' can be things, ideas, people or institutions. Nevertheless, generative behaviours can be motivated by creative self-expression (agency) as well as care (communion) (McAdams \& de St Aubin, 1992). The expected result is wellbeing, because generative contribution involves enjoyment of one’s powers (manifested in what one can do for others) and is channelled towards activities intended to have value for others which often also bring social rewards of recognition, thereby satisfying one’s 'need to be needed' (Bauer \& McAdams, 2004; Staudinger \& Kunzmann, 2005).

Growth and generativity are therefore likely to be central to any comprehensive account of lifeor career development. They are key aspects of a person's functioning, with implications for their wellbeing, work motives and behaviour.

\section{Career Orientations and Stages}


MEN IN MID-LATE CAREER

Because career stages reflect normative age-related societal perceptions and expectations, theorists of aging (Kooij et al, 2011; Sterns \& Doverspike, 1989) have argued that they have considerable potential for enhancing our understanding of subjective and psychosocial aspects of aging, particularly within the context of work. Indeed, inasmuch as they describe age-related motivational change, career stages may more successfully explain work adjustment in middle and later career than chronological age alone (Kanfer \& Ackerman, 2004). Growth and generativity have often been assumed to be characteristic of different phases of career. Traditional theory (e.g. Hall, 1976; Super, Super \& Savickas, 1995) presents career as a sequence of discrete stages, each involving normative developmental tasks and a distinctive configuration of attitudes and behaviour. The years around 45 mark the point at which most people's career trajectory levels off in terms of hierarchical promotion, according to this traditional career stage approach. For the majority, expansive concerns are thought to give way to a more conservative and stationary outlook -'maintenance'- characterized by strategies for preserving past career gains, modest innovation, and keeping pace with change. These developments are often accentuated by recognition that one’s career has plateaued (Super et al., 1995). Concern for achievement, career advancement and new learning (forms of growth) is thought to give way to concern for relationships with fellow-workers and the good of the organization (forms of generativity).

Some limited evidence suggests that job characteristics relevant to growth-such as complexity (Gould, 1979) and challenge (Rabinowitz \& Hall, 1981)-do indeed decline in their importance for positive work attitudes in later stages of career, whilst Zacher et al. (2011) found that a positive association between leader generativity and follower perceptions of leadership effectiveness applied only to the later stages of leaders' careers. However, whilst there is an accumulating body of evidence concerning the relationship between chronological age and growth and generativity, so far the implications of career stages for these constructs have barely been explored (Kooij et al., 2011). 
MEN IN MID-LATE CAREER

The traditional picture of career growth levelling off in midlife finds support in contemporary life-span developmental theory (Baltes, 1997). This presents aging in terms of an increasingly adverse ratio of losses to gains over time as a result of which individuals devote fewer resources to higher levels of functioning (i.e. growth) and relatively more to preserving what they already have (Ebner, Freund \& Baltes, 2006). In contrast to traditional theory, however, contemporary life-span theory also emphasizes developmental plasticity, the reversibility of much apparent decline, and individual differences in available capacity for development (Staudinger \& Bowen, 2010). This suggests that a pre-ordained age-linked sequence of career stages is unlikely to correspond well with people's lives. Therefore, following Super, Thompson \& Lindeman (1988), we construe career stages as subjective orientations towards career; but unlike these authors, we allow the possibility that expansive and conservative orientations may co-exist in this period (Cate \& John, 2007). According to Super (Super et al., 1995), in mid/late career individuals may still be advancing their career, re-cycling it, maintaining it, or disengaging from it. Advancing includes heightened and broadened responsibilities as well as promotion, and can be understood in intrinsic as well as extrinsic ways. Re-cycling can in our view be considered as closely allied to advancing, but manifests in changes in occupational direction and trying out new things. Both advancing and recycling concern expansion of one's personal attributes, and we call the combination "forward momentum". In contrast, as noted above, maintenance is about holding on to existing gains, and keeping up with change.

As an expansive phenomenon, we expect an orientation towards forward momentum to correlate positively with personal growth. Different considerations apply to career maintenance. As a relatively stationary orientation (Super et al., 1995), with development largely confined to concern for specific updating and innovation in the current work role, we expect its correlation with growth to be negative. Hypothesis 1a. Forward momentum career orientation correlates positively with personal growth. 
MEN IN MID-LATE CAREER

Hypothesis 1 b. Maintenance career orientation correlates negatively with personal growth.

Generativity features in many theoretical accounts of career maintenance. It is argued that as desire for personal advancement dwindles, so individuals’ attentions turn from themselves to others. Increasingly, individuals find satisfaction in sponsoring others' careers, for example through a mentoring role (e.g. Hall, 1976; Levinson et al., 1978; Super et al., 1995). Two aspects are especially notable. First, generativity is conceptually linked to career maintenance, not to earlier stages of career. Second, and closely related to this, the self-enhancing concerns of career advancement are contrasted with the other-focused concerns of maintenance. Interpersonal and, in particular, inter-generational generativity take centre-stage. However, this picture is somewhat at odds with what little evidence we have. Allen (2003), for example, found that the desire to mentor declined with age, while Howard and Bray (1988) did not detect evidence of a general trend toward inter-generational generativity among mid-life male managers. The most advanced managers in their study both continued to seek advancement and showed greatest societal concern. In view of the uncertain picture described above, we pose the following question:

Research Question 1: What relationship, if any, is there between maintenance career orientation and generativity?

People who continue to perceive their careers as advancing in mid/late career are likely also engaging with the nurturant roles, such as mentor, ideas leader, or leader of people, which organizations expect of individuals at the more advanced career stages described by Dalton, Thompson and Price (1977). Compared with individuals who see their careers in stationary and less expansive terms, they may be more strongly invested in contribution, and more inclined to appraise their contributions favourably. It is likely therefore that generativity is associated with continuing forward momentum in $\mathrm{mid} / \mathrm{late}$ career.

Hypothesis 2. Forward momentum career orientation correlates positively with generativity. 
MEN IN MID-LATE CAREER

\section{The Role of Personality in Growth and Generativity}

Occupational and organizational psychology is replete with studies of personality due to a longstanding concern with individual differences as predictors and (latterly) potential outcomes of work variables (Hough \& Ones, 2001; Woods, Lievens, De Fruyt \& Wille, 2013), including career behaviours (Ng, Eby, Sorensen \& Feldman, 2005). Specifically in the context of the present study, it may be that personality affects how people construe and manage the challenges inherent in their work (Wille, Beyers \& De Fruyt, 2013). We argue below that certain aspects of personality implicated in life-span development affects growth and generativity in mid-late career, but also that career orientation has separate effects.

Our choice of which personality characteristics to use was informed by life-span development theory (e.g. Bauer \& McAdams, 2004; Staudinger \& Kunzmann, 2005) which suggests that adult development unfolds in two separate but interacting systems, each with its own distinctive trajectory and underlying personality attributes. One pathway represents personality maturity and the other represents psychosocial adjustment. The maturity pathway concerns a process of individuation in which changes in cognition, emotion and motivation lead to increasing complexity and differentiation of the self-system (Bauer \& McAdams, 2004). It is evident in Loevinger's (1976) well-known theory of ego development, and Baltes and Staudinger’s (2000) construct of personal wisdom. Whereas adjustment increases steadily across the lifespan, maturity may peak in early adulthood and stabilize thereafter (Westenberg \& Block, 1993). We assess personality maturity in this study through Loevinger's (1976) construct of ego development.

The adjustment pathway concerns successful mastery of developmental challenges associated with healthy functioning. It associates with subjective well-being and is facilitated by attributes which indicate efficacious, healthy, and adaptive human functioning. The personality trait of ego resiliency 
MEN IN MID-LATE CAREER

reflects this system because it refers to the ability to tolerate anxiety and stress and handle them productively (Block, 1982).

Staudinger and Kunzmann (2005) describe the maturity pathway as relevant to personal growth and the adjustment pathway as relevant to generativity. If this was the case, we would expect ego development to be associated with growth but not generativity, and ego resiliency to be associated with generativity but not growth. The link between maturity and growth is based on the expectation that individuals who have achieved more advanced levels of ego development will have a more complex and developed view of self's potentialities that is reflected in concern for self-fulfilment and personal development (Helson \& Roberts, 1994).The link between the adjustment personality pathway (represented by ego resiliency) and generativity is based on the expectation that ego resiliency predicts the ability to respond successfully to developmental challenges associated with middle age and, indeed, any period of life (Pals, 1999). Erikson (1959) and more recent life-span theorists (e.g. McAdams \& de St Aubin, 1992) argue that generativity is a central developmental task of middle age.

Also in line with Staudinger and Kunzmann's model, we see no reason to expect that maturity (represented by ego development) will be associated with generativity. This is because generativity is mainly focused on other, not self, whereas ego development reflects the internal functioning of the self (de St Aubin \& McAdams, 1995). However, we believe that Staudinger and Kunzmann’s stark contrast between the two pathways breaks down in the case of ego resiliency and growth. Personal growth implies a healthy and efficacious response to challenge (indicative of adjustment) as well as advances in self-complexity (indicative of maturity). Also, several studies (e.g. Kooij et al., 2013; Sheldon \& Kasser, 2001) have found positive associations between personal growth and well-being. We therefore expect that adjustment (represented by ego resiliency) will be positively associated with personal growth.

Hypothesis 3a. Ego resiliency correlates positively with personal growth. 
MEN IN MID-LATE CAREER

Hypothesis 3b. Ego development correlates positively with personal growth.

Hypothesis 3c. Ego resiliency correlates positively with generativity.

\section{Career Orientation and Personality}

In our conception, career orientation comprises a partly bounded, but permeable aspect of a person's career sub-identity (Hall, 1971) which may profoundly influence attitudes and behaviour relevant to work and other aspects of life (Super et al., 1995). Career orientation comprises a distinctive configuration of goals, motives and values, attributes which McAdams (1995) describes as contextspecific and inherently fluctuating in response to both inner and outer circumstance. In contrast, personality traits are commonly considered relatively independent of context, and stable in mature adulthood. Some evidence links specific aspects of personality both to generativity and to personal growth (Cox, Wilt, Olson \& McAdams, 2010; McCrae \& Costa, 2003; Whitbourne, 1986), but fairly weakly. Personality traits have also been found to associate with subjective career variables, but again only weakly (Bozionelos, 2004), with contextual factors playing an equal or stronger role (Ng et al., 2005). We therefore expect the two contrasting orientations represented by forward momentum and career maintenance to predict variance in generativity and personal growth over and above that predicted by personality traits.

Hypothesis $4 a$. Career orientation explains unique variance in personal growth over and above that predicted by personality.

Hypothesis $4 b$. Career orientation explains unique variance in generativity over and above that predicted by personality.

\section{The Relationship between Personal Growth and Generativity}

Thus far, we have portrayed growth and generativity as key features of somewhat different developmental tracks and stages. Does this mean that they are in opposition, or can they happily coexist? As constructs which emerge from different traditions within psychology, there is as yet no 
MEN IN MID-LATE CAREER

consolidated body of theory concerning the relations between personal growth and generativity. From several perspectives, they may be opposing tendencies. Meglino and Korsgaard (2004), for example, contrasted the polar opposites of other-orientation and self-interest, which arguably reflect generativity and growth respectively. Tension between generativity and growth is also implied by recent studies which employ Socio-Emotional Selectivity (SES) theory. Kooij and van de Voorde’s (2011) findings were consistent with SES theory's proposition that self-enhancing tendencies cede priority to otherfocused generative concerns when one's time is perceived to be running out.

However, according to other perspectives within psychology, generativity and personal growth are complementary. Both growth (Ryff, 1989) and generativity (Erikson, 1963) have been advanced as dimensions of positive functioning in adulthood. In Self-Determination Theory, this is because of their shared status as intrinsic motivations (Sheldon \& Kasser, 2001). Some recent empirical evidence (Kooij \& van de Voorde, 2011; Kooij et al., 2013) suggests that generativity and growth motives correlate positively. As a construct which describes effortful mastery of developmental challenges, generativity requires mobilization and enhancement of resources of personality (Erikson, 1963; Snarey, 1993). This should show in a positive relationship with personal growth.

Hypothesis 5. Personal growth and generativity are positively correlated.

\section{Method}

\section{Participants}

Our sample comprised 41 men resident in the United Kingdom, distributed evenly between 45 and 55 (mean age, 50.17). Twenty-four were employees of a large engineering company: ten managers (mainly senior, six responsible for 100 or more professional staff), six specialist engineers (most graded as having national or international standing), and eight shop floor employees, including several supervisors. All were nominated by the company’s HR department. Nine managers, five specialists and one works employee held Bachelor’s degrees; the remaining participants held craft/technician 
MEN IN MID-LATE CAREER

qualifications. Seven members of the sample were Roman Catholic parish priests, comprising all those in the relevant age range within a single diocese who were willing to participate (one declined); and ten were secondary school teachers. The priests had completed six and a half years seminary training. The teachers (including one head teacher and one deputy head) were drawn from seven schools, and volunteered to participate in response to a letter forwarded by their head teachers. All were qualified to Bachelor's degree level or above. Twelve members of the sample held Master's or Doctoral degrees. All were white, and took part voluntarily.

\section{Procedure}

Participants were told that the study concerned 'what individuals want from work between 45 and 55'. Each participated in a lengthy, standardized interview, in which they also completed the career orientation measure described below. Interviews were transcribed in their entirety. Two parts of the interview (around one hour of conversation per participant) were coded. These concerned respectively (1) men's present work role (sources of challenge, satisfaction, and worry; social interaction; and perceived personal change in that role), and (2) critical incidents (occasions of success, disappointment, difficulty, change, conflict, and personal growth). Confidentiality was assured. Participants then completed a package of written measures over the next 2-6 weeks, including those described below.

\section{Written Measures}

Ego resiliency was measured by Klohnen’s (1996) 29-item scale. Sample items include: “My daily life is full of things that keep me interested”, and "I feel like giving up quickly where things go wrong” (reverse scored). Items were rated against a 5-point scale ranging from Strongly disagree (1) to Agree strongly (5). Coefficient alpha in the present study was .89. In support of the assumption that ego resiliency reflects the adjustment developmental pathway, it correlated highly significantly $(r=.75, p<$ 
MEN IN MID-LATE CAREER

.001) with a three-item life satisfaction measure drawn from Hawley’s (1988) Measures of Psychosocial Development (MPD).

Ego development was measured by the Washington University Sentence Completion Test (WUSCT) (Hy \& Loevinger, 1996). Whereas adjustment-related concerns present themselves to individual awareness and are therefore relatively easily measured via self-report, maturity concerns systematic changes in the sense-making structure which shapes individuals' assumptions about reality. It is measured through time-intensive and often laborious projective means (Staudinger \& Bowen, 2010). The WUSCT is a projective measure that requires participants to complete 36 sentence stems such as "When a child will not join in a group activities...”, "What gets me into trouble is...”, and “Sometimes he wished that...”. Studies which have explored the properties of Loevinger’s instrument (reviewed in Hauser, 1993) report high levels of psychometric reliability and extensive empirical support for her model of ego development. WUSCT protocols were rated and scored by the first author in accordance with Hy and Loevinger's (1996) manual after he had achieved 85\% and above accuracy in its reliability checks (c.f. Bauer \& McAdams, 2004). The cumulative frequency of item ratings was converted into a single overall score, following ogive rules (Hy \& Loevinger, 1996). Out of nine possible ego developmental levels described by these authors, only seven are commonly found in adults. Incidence in the present study was: E3 Impulsive (0 individuals), E4 Conformist (3), E5 SelfAware (21), E6 Conscientious (13), E7 Individualistic (3), E8 Autonomous (1), and E9 Integrated (0). Following widely accepted practice (e.g. Helson \& Roberts, 1994), we interpreted ego development as an interval scale (scored from 1=lowest to 9=highest) for the purposes of correlational and regression analyses (in the present sample E4 Conformist=4 points to E8 Autonomous=8 points). Consistent with the dual-track model of adult development (Staudinger \& Kunzmann, 2005), ego development was not significantly correlated with ego resiliency $(r=-.03, n s)$. 
MEN IN MID-LATE CAREER

Personal growth. This was assessed by four items from Hawley’s (1988) MPD. These measure appetite for challenge, learning and fulfilment. Item content closely approximates to the construct assessed by well-established and more recent measures of personal growth in the work psychology literature (e.g. Kooij et al., 2013; Schneider \& Alderfer, 1973). The items were "Eager to learn and develop my skills”, "Seek out new projects and undertakings”, “Like to experiment and try new things", and "Finding new avenues of self-fulfilment”. Participants rated on a 5-point scale the degree to which they resembled each item $(1=$ Not at all like me, to $5=$ Very much like me). Alpha was .87.

Generativity was measured by the Loyola Generativity Scale (LGS) (McAdams \& de St Aubin, 1992). Although its authors described the LGS as assessing concern for generativity, we argue elsewhere (Clark \& Arnold, 2008) that this widely employed scale is better understood as a measure of successful accomplishment of generativity. Items seek participants’ agreement with self-descriptive statements (e.g., "I have made and created things which have had an impact on other people”, "I have important skills that I try to teach others”, and “Others would say that I have made unique contributions to society”) along a 5-point scale ranging from Strongly disagree (0) to Strongly agree (4). Alpha in the present study was .88 .

Career orientation. Participants distributed 100 points between five items based on Super’s career stages (Super et al., 1995). According to Super, in mid/late career individuals may be advancing their career, re-cycling it, maintaining it, or disengaging from it. We added to this reviewing (Murphy \& Burck, 1976). Only the first three orientations are central to the present paper. In contrast to the common practice of classifying individuals in relation to a single stage only, we assumed that different tendencies co-exist in mid/late career, a period of flux for many (Levinson et al., 1978). Our ipsative approach reflected our belief that these tendencies not only co-exist, but often compete.

Forward momentum in career comprised men's summed scores for Advancing and Re-cycling. Advancing comprised: “Continuing to advance my career in my chosen occupation. Expanding and 
MEN IN MID-LATE CAREER

enhancing my contribution. Taking on new roles. Breaking new ground. Looking to move onwards and upwards". Recycling was defined as "Embarking on a new career, or a major change of direction in my career. Exploring my potential in a new field. Seeking work that suits my abilities, and matters to me, at this time of my life”. Maintenance comprised: "Have reached my level in my chosen occupation. Striving to maintain my position by doing a good job and keeping up with change. Holding my own and preserving what I have accomplished. Content to find new challenges in the same role and new ways of doing old things”.

\section{Narrative Measures}

The self-report growth and generativity scales used in this study (see above) imply an efficacious, confident, and optimistic view of self. This risks over-simplifying constructs which research has found to be complex and multi-faceted (McAdams \& de St Aubin, 1992; Stewart \& Vandewater, 1998). Interviews may be more successful than self-report measures in bypassing global self-perceptions since, as partly ‘operant’ measures (Emmons \& King, 1992), they offer fewer cues concerning researchers’ intentions. Following established practice (Peterson \& Stewart, 1993; Smith, Feld \& Franz, 1992) we therefore derived measures of growth and generativity from interview narratives. These assess wanting, trying, and managing to grow and to be generative in specific, messy, contingent, everyday contexts where individuals may not be confident of success. We regard our narrative measures as assessing motivational and behavioural investment in growth and generativity.

Drawing on many authors, we compiled detailed coding manuals separately for growth and generativity (available from the second author on request). Participants' scores for personal growth aggregated two themes. Learning referred to acquisition of skills, knowledge, understanding, and abilities, whether through formal learning or experience. Fulfilment concerned more complete realization of self through seeking out and engaging with challenge; using a wide variety of skills; discovering and developing new attributes; and attaining greater fullness or completeness as a person. 
MEN IN MID-LATE CAREER

Generativity. We sought evidence of generativity in a wide range of work-related activities which reflect a person's concern for others, desire to improve collective well-being (including but not confined to future generations), leadership, organizational citizenship, and prosocial behaviour, including mentoring. Drawing upon Stewart, Franz, Paul \& Peterson (1991), our coding of generativity comprised four themes: care for others' well-being, care for others' growth (e.g. in the context of mentoring, coaching, supervisory, teaching or preaching roles), societal concern (care at a collective level for the well-being of society in general or some part of it, including the employing organization), and leadership and prosocial impact (leading, managing, influencing people and organizations).

Scoring of growth and generativity. Where a generativity or growth theme was identified, we assessed its status as a concern (i.e. an opinion, self-perception, interest, belief, or preference), commitment (i.e. a goal, or what someone was trying to accomplish), or action (in the case of generativity, a physical behaviour; in the case of growth, a change of state) (McAdams \& de St Aubin, 1992). Coding for both personal growth and generativity also distinguished between work and nonwork. Men’s non-work generativity themes generally concerned their public roles e.g. as a magistrate or school governor, or in leadership roles within voluntary groups, which many authors (e.g. Howard \& Bray, 1988; Super et al., 1995) treat as an extension of career.

Following Stewart et al. (1991), the basic unit of coding was the meaningful phrase. Coding was conservative: ambiguous phrases were excluded. Each passage was coded in isolation from other information about a participant, including other parts of the interview. Interviews were coded by the first author. Following Smith et al. (1992), a 25\% sample was coded by the second author who was blind to other information about participants and to the research hypotheses. Inter-coder agreement (calculated in accordance with Smith et al., 1992) was good for generativity (90.7\%), acceptable for growth (75.7\%), and satisfactory for the domains of concern, commitment, and action (82.8\%). 
MEN IN MID-LATE CAREER

Scoring scheme. Men's interview narratives were scored separately for the presence (1 point) or absence (0) of each generativity or growth theme in each of the three domains of concern, commitment and action (i.e. up to three points per theme). The two life contexts of work and non-work were scored separately, as also were the two parts of the interview (i.e. present work role and critical incidents). Scores for each theme were summed. Consequently, across both parts of the interview, participants could score a maximum of twelve points (i.e. 3 × 2 × 2) for each of the four generativity and two growth themes. Our scoring scheme thus assessed intensity (i.e. incidence of a particular theme), depth (i.e. alignment of the domains of concern/commitment/action), breadth (i.e. expression of different themes) and scope (work/non-work contexts) of generativity and growth in men's selfnarration. Within the personal growth category, aggregated scores for the learning theme correlated fairly strongly $(r=.56, p<.001)$ with those for the fulfilment theme. The two items were therefore combined into a single personal growth measure (alpha $=.71)$ for the purpose of the analyses reported below. Among the generativity themes, five out of six inter-correlations attained at least marginal significance, ranging between .23 and .57. These themes were therefore aggregated into an overall generativity score (alpha also .71). However, in Table 1 we also show the individual generativity themes, as occasionally there is reason to note differences between them. The two personal growth themes correlated very similarly with other variables, and are therefore not presented separately.

\section{Results}

\section{INSERT TABLE 1 ABOUT HERE}

\section{Descriptive Findings}

Descriptive statistics and zero-order correlations are shown in Table 1. Averaged across participants, career maintenance $(M=42.44, S D=30.99)$ was higher than forward momentum $(M=$ 34.76, $S D=29.28$ ), but their means were not significantly different. Within forward momentum, mean 
MEN IN MID-LATE CAREER

score for Advancing was 27.32, SD 26.81, and for Recycling 7.44, SD 12.15. The large standard deviations point to widely differing outlooks on career in this period. Eight men, or one in five, reported little or no forward momentum in career (i.e. fewer than 10 points out of 100). At the other extreme, two in five scored higher for forward momentum than for maintenance. Age correlated significantly with the generativity theme of Care for others' well-being ( $r=.36, p<.05$ ), and its associations with overall generativity $(r=.26, p<.10)$ and forward momentum $(r=-.26, p<.10)$ also approached significance. Although weak, these trends are similar to those observed by Zacher et al. (2011, 2012). Age was unrelated to growth in self-report (.07 ns), or interview narratives (-.07 ns).

Alignment between our self-report and narrative measures was stronger for generativity $(r=.69$, $p<.001)$ than for personal growth $(r=.33, p<.05)$. As our narrative and self-report personal growth constructs resembled each other closely, the latter seems therefore to explain only part of the motivation underlying men’s experience of personal growth. Ego resiliency (adjustment) and ego development (maturity) were non-significantly correlated. Furthermore, ego development was nonsignificantly correlated with all six measures of generativity, five of which were statistically independent of each other. In only one case (societal generativity) did the correlation with ego development approach significance $(r=.26, p=.11)$. Our results for generativity therefore were largely consistent with Staudinger and Kunzmann’s (2005) theory concerning the independence of adjustment and personality maturity.

\section{Tests of Hypotheses}

Hypothesis 1a stated that forward momentum career orientation correlates positively with personal growth. This was supported both for the self-report measure of desire for growth and for the interview narrative measure of growth $(r=.40, p<.01$ and $r=.38, p<.05$ respectively).

Hypothesis $1 \mathrm{~b}$ stated that maintenance career orientation correlates negatively with personal growth. This was supported for both growth measures: $r=-.40 p<.01$ for desire for growth, and $r=$ - 
MEN IN MID-LATE CAREER

$.38, p<.05$ for narrative growth. Taking Hypotheses $1 \mathrm{a}$ and $1 \mathrm{~b}$ together, there is strong evidence that career orientations and growth are connected in mid-late career.

Research Question 1 concerned the relationship between maintenance career orientation and generativity. The correlation between maintenance and narrative generativity was significant and negative $(r=-.48, p<.01)$. Societal concern was the most strongly implicated aspect of generativity. The correlation between maintenance and LGS was negative ( $r=-.17)$ but non-significant. Overall, then, a maintenance career outlook may stifle generativity rather than encourage it.

Hypothesis 2 was that forward momentum career orientation correlates positively with generativity. From Table 1, it can be seen that forward momentum correlated $r=.38(p<.05)$ with the interview narrative measure of overall generativity. The relationship was most marked for the societal concern component of generativity $(r=.46, p<.01)$. Forward momentum also correlated $r=.37(p<$ .05) with LGS self-report generativity. Hypothesis 2 was therefore supported.

Hypothesis 3a stated that ego resiliency correlates positively with personal growth. Ego resiliency correlated significantly with desire for growth $(r=.40, p<.05)$ but not with narrative growth $(r=.16$, ns), thus giving partial support to Hypothesis 3a. Hypothesis 3b predicted that ego development correlates positively with personal growth. Ego development was strongly correlated with narrative growth $(r=.62, p<.001)$ but not with desire for growth $(r=.15, n s)$, thus also giving partial support to Hypothesis 3b but with a different growth measure than for ego resiliency. In short, there was evidence of an association between growth and both adjustment (ego resiliency) and maturity (ego development).

There was strong support (Hypothesis 3c) for the association of adjustment (ego resiliency) with generativity. Ego resiliency correlated $r=.44(p<.01)$ with narrative overall generativity. Supporting others' growth was the most strongly implicated aspect of generativity. Notably, the correlation 
MEN IN MID-LATE CAREER

between ego resiliency and LGS self-report generativity was especially high at .75, despite the very different item content of the two measures.

Hypothesis 4a proposed that career orientation explains unique variance in personal growth over and above that predicted by personality. To test this, we regressed the two personal growth measures on the two personality measures (step 1) and then added the two career orientation measures (step 2).

Findings are shown in Table 2. For neither growth measure did the two career orientation variables add significantly to the explained variance. On the other hand, ego development was strongly associated with narrative growth, and ego resiliency was weakly associated with desire for growth.

Hypothesis 4b stated that career orientation explains unique variance in generativity over and above that explained by personality. We conducted similar regressions to those described above, using LGS and narrative overall generativity as the two dependent variables. Results appear in Table 2, and regarding career orientation are very similar to those for growth. The two career orientation variables did not add significantly to the variance in generativity explained by the two personality variables. Ego resiliency on the other hand was a strong predictor of both generativity measures. Ego development was not. These findings largely bear out the correlational results outlined above, and suggest that generativity in mid-late career requires an inner strength more than a particular career orientation.

INSERT TABLE 2 ABOUT HERE

Hypothesis 5 proposed that personal growth and generativity are positively correlated. This was strongly supported in the case of desire for growth, which correlated $r=.53(p<.001)$ with LGS generativity, and $r=.46(p<.01)$ with narrative overall generativity. Support was more limited in the case of narrative growth, but still present. The correlation of narrative growth with LGS was nonsignificant, and with narrative overall generativity it neared significance $(r=.28, p<.1)$, with societal 
MEN IN MID-LATE CAREER

concern $(r=.40, p<.01)$ the main contributor. Consistent with findings reported above, correlations tended to be higher within method (i.e. self-report or interview narrative) than between methods.

\section{Discussion}

Our study gathered multi-method data from 41 men aged between 45 and 55 to explore two constructs which, according to life-span developmental theory, are central to a positive experience of mid-late career: personal growth and generativity. We sought their potential antecedents in two contrasting but sometimes co-existing orientations toward career (forward momentum and maintenance) which are thought to fluctuate in this period. We also examined two comparatively stable personality traits, ego resiliency and ego development (representing distinct but interacting paths of personality development) as potential antecedents of personal growth and generativity. This study therefore combines constructs from work and organizational psychology with life-span developmental psychology in order to scrutinize career development from novel perspectives. We argue that despite our small sample, this study has some significant methodological strengths, including the diverse occupations held by the 41 men, our use of both self-report and coded interview narrative measures of personal growth and generativity, and the minimization of common method variance by administration of the career orientation measure on a separate occasion from the self-report measures of growth and generativity.

A forward momentum career orientation was quite strongly positively associated with personal growth, and with generativity. In contrast, a maintenance career orientation was negatively related to both our measures of personal growth, and to generativity in interview narratives. As hypothesized, the personality characteristic of ego resiliency was quite strongly associated with generativity. Ego resiliency was also associated with desire for growth, but it was the level of ego development (i.e. a maturity-related personality construct rather than an adjustment-related one) that was associated with the personal growth men described in their interviews. Regression analyses showed that career 
MEN IN MID-LATE CAREER

orientation did not add significantly to variance explained in growth and generativity after personality was accounted for.

Our findings also indicate that growing as an individual and giving to others are not mutually exclusive at this career stage - in fact, rather the opposite. This fits with McAdams’ idea that generativity comprises a fusion of agency and communion and that agency is inherent even in otherfocused forms of contribution. It is also consistent with findings (e.g. Grant \& Mayer, 2009; Grant \& Wade-Benzoni, 2009; Newton, Herr, Pollack \& McAdams, 2014) that self-serving motivation can reinforce prosocial contribution. The strength of the association we found (circa .40) corroborates that reported by Kooij and van de Voorde (2011). However, our findings significantly extend theirs, through our use of interview measures as well as self-report, and through the more diverse expressions of generativity we investigated. The fact that the societal concern element of narrative generativity tended to be the most highly correlated with other variables, including career orientations, is a useful complement to the research of Zacher and colleagues (e.g. 2011, 2012) on the more interpersonal "bringing on the next generation” manifestations of generativity. Taken together, those studies and this one attest to the significance of the generativity construct.

The roles of two personality traits in generativity and personal growth are clarified in our study. Consistent with Staudinger and Kunzmann’s (2005) theory, ego resiliency but not ego development was correlated with both measures of generativity, and this relationship was maintained even when controlling for ego development and the two career orientations. Ego resiliency is clearly an important psychological asset in this period. Not only were resilient individuals more invested in generativity (as shown by our narrative measure) than less resilient peers, and inclined to rate their generative contribution more highly (as shown by the LGS), they also tended to perceive self and career in more expansive terms. Resiliency may therefore be at the heart of positive attitudes in this period. Also consistent with this theory, ego development predicted growth, and this relationship too remained 
MEN IN MID-LATE CAREER

significant controlling for other variables (see Table 2). Specifically, individuals who scored higher for this measure of maturity differed from less mature peers in narrating their career as a dynamic process of learning and self-fulfilment, even though they were no more likely to show the challenge orientation measured by our self-report measure of growth. Ego development has previously been implicated in accommodative growth, where identity is reframed in response to traumatic, life-changing events or transitions (e.g. Bauer \& McAdams, 2004; King, Scollon, Ramsey \& Williams, 2000), but we believe our study is the first to show a concurrent link between ego development and expansive personal growth in the workplace.

Overall, the two personality variables predicted variance in personal growth and generativity but the two career orientation measures did not add significantly to that. This suggests that growing as a person and contributing to others are more a function of core personality than of subjective career stage, at least around age 50. This has important potential implications for careers research, where orientations toward career are often positioned as determinants of outcome variables (c.f. Baruch \& Sullivan, 2009). Our findings suggest that personality may underlie both, and therefore needs to be not merely controlled but actively investigated. Even so, in our regression analyses, the maintenance career orientation had negative relationships that approached significance with the narrative measures of both growth and generativity, after controlling for personality (see Table 2). This leaves open the possibility that maintenance may play a role in supressing growth and generativity independent of personality. However, given the high negative correlation between maintenance and forward momentum career orientations, it is necessary to be cautious in specifying which of them is doing the work.

Indeed, the implications of our findings regarding career maintenance are thought-provoking. Maintenance appears to signal a lack of engagement with both growth and generativity. The former can be expected from existing theory. The latter cannot, although it is consistent with the scant empirical evidence. Growth and generativity are often considered intrinsic motivations; it makes sense therefore 


\section{MEN IN MID-LATE CAREER}

that they correlated quite strongly with our forward momentum career orientation measure. In contrast, the negative association of maintenance with our measure of intrinsic concern for growth (desire for growth) suggests that people with a career maintenance mind-set in mid-late career are likely to show low levels of intrinsic motivation. Our results indicate that organizations may struggle to elicit a generative contribution or interest in learning and self-improvement from individuals whose outlook is maintenance. Mentoring is often prescribed as a solution for individuals whose careers have plateaued, but for our respondents it was not a frequently discussed expression of generativity. Our study suggests that mentoring may only appeal to plateaued individuals who are intrinsically motivated. Consequently, in order to elicit a mentoring contribution, organizations need strong generative/learning-related norms and to offer extrinsic rewards of recognition and pay to individuals with a maintenance outlook on career.

However, generativity is not confined to mentoring. It is also relevant to core roles, such as leader (c.f. Zacher et al., 2012) and to concerns for broader organizational and societal well-being. Organizational interventions therefore need to be guided by a differentiated and comprehensive understanding of generativity. This is an opportunity: generativity can be expressed in a variety of ways that help to sustain individuals, organizations and communities.

Finally, we consider methods. Narrative and self-report measures were quite strongly correlated with each other for generativity, and their correlations with other variables were also fairly consistent. However, this consistency between methods was less evident for personal growth. As a widely espoused value in Western organizations and society more generally, growth likely encourages socially desirable responses to questionnaire items that offer explicit cues. In contrast, interviews which offer fewer cues concerning the researchers’ intentions may be comparatively - although certainly not completely - successful in bypassing socially desirable response patterns. In other words, as a form of projective test (c.f. Emmons \& McAdams, 1991), they resemble operant measures which are well- 
MEN IN MID-LATE CAREER

suited to assessment of implicit constructs which bypass conscious awareness. Also, the self-report growth measure assessed a construct which is widely regarded as intrinsic (Amabile, 1993; Ryan, 1995); as such it would be expected theoretically to associate with favourable personality adjustment. However, Bailyn (1980) suggested that among extrinsically motivated individuals, learning and development (i.e. growth) are sought not for their own sake, but for career advancement. Our interview narratives likely picked up some extrinsically motivated growth which would be missed by the selfreport measure. Clearly, therefore, growth themes present in narratives reflect a complex motivational phenomenon and may be at least partly a response to external demands separate from both personality and career orientation.

\section{Limitations}

Our study is limited by its sample size and its exclusion of women. Occupational differences were not the central interest of this study, where our main concern was to ensure diversity within an inevitably small sample given the resource-intensive nature of the data collection. At the moment we can only speculate concerning the implications of our investigation for employment contexts where, unlike the present sample, the one life - one career pattern (Sarason, 1977) is not the norm.

Our career orientation measure may have exaggerated the contrast between forward momentum and career maintenance. The men were asked to distribute 100 points between a total of five career concerns, of which only advancement, recycling (together constituting forward momentum) and maintenance are reported here. Therefore forward momentum and maintenance were partially ipsative. Nevertheless, it was possible for respondents to assign considerable (or little) importance to both, and some did. Also, we avoided using the term maintenance because it seemed rather jargonized. Instead, we used the term "Hanging in there”. Despite the fairly upbeat description provided to respondents for this career orientation (see Method section), its label may have had more negative connotations than we intended. We did not use scores for the career orientations of disengagement and reviewing (means 
MEN IN MID-LATE CAREER

respectively 7.1 and 15.7) in our theorizing. This seems justified because between them they showed just one significant correlation (out of 20) with personality, generativity and growth measures (reviewing with ego resiliency, $r=-.32, p<.05$ ).

A further limitation concerns the cross-sectional and age-limited nature of our study, which prevents us from saying how far the picture of growth and generativity we uncovered, or indeed the ratio of career growth to maintenance, may apply to earlier or later periods of career. Still, the measures of career orientation were taken on a different occasion from the other self-report measures, which likely helped to minimize biases and common method variance.

\section{Directions for Future Research}

Further research could examine the generalizability of our findings across ages, genders, occupations and career stages. Do some people consider themselves in career maintenance even at (say) age 30 ? If so, does this frame of mind have the same negative correlates as it does in this study? Given the typically different rhythms of women’s careers from men’s (O’Neil \& Bilimoria, 2005), do women have more of a forward momentum career orientation than men around age 50, and if so, does that show up in greater growth and generativity, as one would expect from the findings reported here?

Theory suggests - and an accumulating body of research (e.g. McAdams \& de St Aubin, 1992; Newton \& Stewart, 2010) confirms - that generativity in the broad sense we describe increases with age. It is therefore important to our understanding of motivation and performance in middle and later career (Kanfer \& Ackerman, 2004). We consequently need a fuller picture of the contours of generativity, and measures which accurately reflect them. This would enable exploration of its antecedents, its different expressions and the relationships between them, and their respective relations with personal growth and other correlates such as well-being. Although a valuable global measure of generativity, we would argue that the LGS is poorly suited to this more differentiated purpose. 
MEN IN MID-LATE CAREER

\section{References}

Alderfer, C. P. (1972). Existence, Relatedness and Growth: Human Needs in Organizational Settings. New York: Free Press.

Allen, T. D. (2003). Mentoring others: A dispositional and motivational approach. Journal of Vocational Behavior, 62, 134-154. doi:10.1016/S0001-8791(02)00046-5

Amabile, T. M. (1993). Motivational synergy: Toward new conceptualizations of intrinsic and extrinsic motivation in the workplace. Human Resource Management Review, 3, 185-201 doi:10.1016/1053-4822(93)90012-S

Clark, M., \& Arnold, J. (2008). The nature, prevalence and correlates of generativity among men in middle career. Journal of Vocational Behavior, 73(3), 473-484. doi/10/1016/j.jvb.2009.09.002

Bailyn, L. (1980). Living with technology: Issues at mid-career. Cambs, MA: MIT.

Baltes, P. B. (1997). On the incomplete architecture of human ontogeny: Selection, optimization, and compensation as foundation of developmental theory. American Psychologist, 52, 366-380. doi: 10.1037/0003-066X.52.4.366

Baltes, P. B., \& Staudinger, U. M. (2000). Wisdom: A metaheuristic to orchestrate mind and virtue toward excellence. American Psychologist, 55, 122-136. doi:10.1037/0003-066X.55.1.122

Bauer, J., \& McAdams, D. P. (2004). Personal growth in adults' stories of life transitions. Journal of Personality, 72, 573-602. doi:10.1111/j.0022-3506.2004.00273.x

Block, J. (1982). Assimilation, accommodation, and the dynamics of personality development. Child Development, 53, 281-295. doi:10.1111/1467-8624.ep8587768

Bozionelos, N. (2004). The relationship between disposition and career success: A British study. Journal of Occupational and Organizational Psychology, 77(3), 403-420. doi: 10.1348/0963179041752682 
MEN IN MID-LATE CAREER

Cate, R. A., \& John, O. P. (2007). Testing models of the structure and development of future time perspective: Maintaining a focus on opportunities in middle age. Psychology and Aging, 22, 186-201. doi:10.1037/0882-7974.22.1.186

Cox, K. S., Wilt, J., Olson, B., \& McAdams, D. P. (2010). Generativity, the Big Five, and psychosocial adaptation in midlife adults. Journal of Personality 78, 1185-1208. doi:10.1111/j.1467-6494.2010.00647.x

Dalton, G. W., Thompson, P. H., \& Price, R. L. (1977). The four stages of professional careers: A new look at performance by professionals. Organizational Dynamics, 6, 19-42. doi:10.1016/00902616(77)90033-X

De St Aubin, E., \& McAdams, D. P. (1995). The relations of generative concern and generative action to personality traits, satisfaction/happiness with life, and ego development. Journal of Adult Development, 2, 99-112. doi:10.1007/BF02251258.

Demiray, B., \& Bluck, S. (2014). Time since birth and time left to live: Opposing forces in constructing psychological wellbeing. Ageing and Society, 34, 1193-1218. doi:

10.1017/S0144686X13000032

Ebner, N. C., Freund, A. M., \& Baltes, P. B. (2006). Developmental changes in personal goal orientation from young to late adulthood: From striving for gains to maintenance and prevention of losses. Psychology and Aging, 21, 664-678. doi:10.1037/0882-7974.21.4.664

Emmons, R. A. \& King, L. A. (1992). Thematic analysis, experience sampling, and personal goals. In C. P. Smith (Ed), Motivation \& personality: Handbook of thematic content analysis. Cambridge: Cambridge University Press.

Emmons, R. A., \& McAdams, D. P.(1991). Personal strivings and motive dispositions: Exploring the links. Personality and Social Psychology Bulletin, 17, 648-654.

doi:10.1177/0146167291176007 
MEN IN MID-LATE CAREER

Erikson, E. H. (1959). Identity and the life cycle. New York: Norton.

Erikson, E. H. (1963). Childhood and society ( $2^{\text {nd }}$ Ed). New York: Norton.

Erikson, E. H., Erikson, J. M., \& Kivnick, H. Q. (1986). Vital involvement in old age. New York: Norton.

Gould, S. (1979). Age, job complexity, satisfaction and performance. Journal of Vocational Behavior, 14, 209-223. Doi:10.1016/0001-8791(79)90071-X

Grant, A. M. \& Mayer, D. M. (2009). Good soldiers and good actors: Prosocial and impression management motives as interactive predictors of affiliative citizenship behaviors. Journal of Applied Psychology, 94, 900-912. doi:10.1037/a0013770

Grant, A. M., \& Wade-Benzoni, K. A. (2009). The hot and cool of death awareness at work: Mortality cues, aging, and self-protective and prosocial motivations. Academy of Management Review, 34, 600-622. doi:10.5465/AMR.2009.44882929

Hall, D. T. (1971). A theoretical model of career subidentity development in organizational settings. Organizational Behavior \& Human Performance, 6, 50-76. doi:10.1016/0030-5073(71)90005-5

Hall, D. T. (1976). Breaking career routines: Midcareer choice and identity development. In D. T. Hall (Ed), Careers in organizations. New York: Scott, Foresman.

Hall, D. T., \& Rabinowitz, S. (1988). Maintaining employee involvement in a plateaued career. In M. London \& E. Mone (Eds), Career Growth and Human Resource Strategies: The role of the human resource professional in employee development. New York: Quorum Books.

Hauser, S. T. (1993). Loevinger's model and measure of ego development: A critical review, II. Psychological Inquiry, 4, 23-30. doi:10.1207/s15327965pli0401_4

Hawley, G. (1988). Measures of Psychosocial Development: Professional manual. Odessa, Florida: Psychological Assessment Resources. 
MEN IN MID-LATE CAREER

Helson, R., \& Roberts, B. W. (1994). Ego development and personality change in adulthood. Journal of Personality and Social Psychology, 66, 911-920. doi:10.1037/0022-3514.66.5.911

Hough, L. M., \& Ones, D. S. (2001). The structure, measurement, validity, and use of personality variables in industrial, work, and organizational psychology. In N. Anderson, D. S. Ones, \& C. Viswesvaran (Eds.) Handbook of Industrial, Work and Organizational Psychology, Vol.1, 233277.

Howard, A., \& Bray, D. W. (1988). Managerial lives in transition: Advancing age and changing times. New York: Guilford Press.

Hy, L. X. \& Loevinger, J. (1996). Measuring ego development (2 ${ }^{\text {nd }}$ ed.). Mahweh, NJ: Lawrence Erlbaum.

Kanfer, R., \& Ackerman, P. L. (2004). Aging, adult development, and work motivation. Academy of Management Review, 29, 440-458. doi:10.5465/AMR.2004.13670969

King, L. A., Scollon, C. K., Ramsey, C., \& Williams, T. (2000). Stories of life transition: Subjective well-being and ego development in parents of children with Down Syndrome. Journal of Research in Personality, 34, 509-536. doi:10.1006/jrpe.2000.2285

Klohnen, E. C. (1996). Conceptual analysis and measurement of the construct of ego-resiliency. Journal of Personality and Social Psychology, 70, 1067-1079. doi:10.1037//00223514.70.5.1067

Kooij, D., De Lange, A., Jansen, P., \& Dikkers, J. (2013). Beyond chronological age: Examining perceived future time and subjective health as age-related mediators in relation to work-related motivation and well-being. Work \& Stress, 27, 88-105. doi:10.1080/02678373.2013.769328

Kooij, D., De Lange, A., Jansen, P, Kanfer, R., \& Dikkers, J. (2011). Age and work-related motives: Results of a meta-analysis. Journal of Organizational Behavior 32, 197-225. doi:10.1002/job.665 
MEN IN MID-LATE CAREER

Kooij, D., \& van de Voorde, K. (2011). How changes in subjective general health predict future time perspective, and development and generativity motives over the lifespan. Journal of Occupational and Organizational Psychology 84, 228-247. doi:10.1111/j.20448325.2010.02012.x

Levinson, D. J., Darrow, C. N., Klein, E. B., Levinson, M. H., \& McKee, B. (1978). The seasons of a man's life. New York: Alfred \& Knopf.

Loevinger, J. (1976). Ego Development: Conceptions and theories. San Francisco: Jossey-Bass

Magnus, G. (2008). The age of aging. London: Wiley.

Maslow, A. H. (1970). Motivation and personality. $3^{\text {rd }}$ Ed. New York: Harper \& Row.

McAdams, D. P. (1995). What do we know when we know a person? Journal of Personality, 63, 365396. doi:10.1111/j.1467-6494.1995.tb00500.x

McAdams, D. P., \& de St Aubin, E. (1992). A theory of generativity and its assessment through selfreport, behavioral acts, and narrative themes in autobiography. Journal of Personality \& Social Psychology, 62, 1003-1015. doi:10.1037/0022-3514.62.6.1003

McCrae, R. R., \& Costa, P. T. (2003). Personality in Adulthood: A five-factor theory perspective. NY: Guilford.

Meglino, B. M., \& Korsgaard, A. (2004). Considering rational self-interest as a disposition: Organizational implications of other orientation. Journal of Applied Psychology, 89, 946-959. doi:10.1037/0021-9010.79.6.836

Murphy, P. P., \& Burck, H. D. (1976). Career development of men at mid-life. Journal of Vocational Behavior, 9, 337-343. doi:10.1016/0001-8791(76)90061-0

Newton, N. J., Herr, J. M., Pollack, J. L., \& McAdams, D. P. (2014). Selfless or selfish? Generativity and narcissism as components of legacy. Journal of Adult Development, 21, 59-68. doi:10.1007/s10804-013-9179-1 
MEN IN MID-LATE CAREER

Newton, N. J., \& Stewart, A. J. (2010). The middle ages: Change in women's personalities and social roles. Psychology of Women Quarterly, 34, 75-84. doi:10.1111/j.1471-6402.2009.01543.x

Ng, T. W. H., Eby, L. T., Sorensen, K. L., \& Feldman, D. C. (2005). Predictors of objective and subjective career success: A meta-analysis. Personnel Psychology, 58, 367-408. doi:10.1111/j.1744-6570.2005.00515.x

O'Neil, D. A., \& Bilimoria, D. (2005). Women's career development phases: idealism, endurance, and reinvention. Career Development International, 10, 168-189. doi:10.1108/13620430510598300.

Pals, J. L. (1999). Identity Consolidation in Early Adulthood: Relations with Ego-Resiliency, the Context of Marriage, and Personality Change. Journal of Personality, 67, 295-329. doi:10.1111/1467-6494.00057

Peterson, B. E., \& Stewart, A. J. (1993). Generativity and social motives in young adults. Journal of Personality \& Social Psychology, 65, 186-198. doi:10.1037/0022-3514.65.1.186

Rabinowitz, S., \& Hall, D. T. (1981). Changing correlates of job involvement in three career stages. Journal of Vocational Behavior, 18(2), 138-144. Doi:10/1016/0001-8791(81)90002-6

Rogers, C. R. (1961). On becoming a person. Boston: Houghton Mifflin.

Ryan, R. M. (1995). Psychological needs and the facilitation of integrative processes. Journal of Personality, 63, 397-427. doi:10.1111/j.1467-6494.1995.tb00501.x

Ryff, C. D. (1989). Happiness is everything, or is it? Explorations on the meaning of psychological well-being. Journal of Personality and Social Psychology, 73, 1069-1081. doi:10.1037/00223514.57.6.1069

Sarason, S. B. (1977). Work, aging, and social change: Professionals and the one life-one career imperative. New York: Free Press. 
MEN IN MID-LATE CAREER

Schneider, B., \& Alderfer, C. P. (1973). Three studies of measures of need satisfaction in organizations. Administrative Science Quarterly, 18, 498-505.

Sheldon, K. M., \& Kasser, T. (2001). Getting older, getting better? Personal strivings and psychological maturity across the lifespan. Developmental Psychology, 37, 491-501.

Smith, C. P., Feld, S. C., \& Franz, C. E. (1992). Methodological considerations: Steps in research employing content analysis systems. In C. P. Smith (Ed), Motivation \& personality: Handbook of thematic content analysis. Cambridge: Cambridge University Press.

Snarey, J. (1993). How fathers care for the next generation: A four-decade study. Cambridge, MA: Harvard University Press.

Staudinger, U. M., \& Bowen, C. E. (2010). Life-span perspectives on positive personality development in adulthood and old age. In M. Lamd \& A. Freund (eds.), The handbook of life-span development. Hoboken, NJ: Wiley.

Staudinger, U. M. \& Kunzmann, U. (2005). Positive adult personality development: Adjustment and/or growth. European Psychologist, 10, 320-329. doi:10.1027/1016-9040.10.4.320

Sterns, H. L., \& Doverspike, D. In I. L. Goldstein \& R. Katzel (Eds.), Training and development in organizations: Frontiers of industrial and organizational psychology (pp. 299-332). San Francisco, CA, US: Jossey-Bass.

Stewart, A. J., Franz, C. E., Paul, E., \& Peterson, B. E. (1991). Revised coding manual for three aspects of adult development: Identity, intimacy and generativity. Unpublished manuscript.

Stewart, A. J, \& Vandewater, E. A. (1998). The course of generativity. In D. P. McAdams, \& E. de St. Aubin (Eds.), Generativity and adult development: Psychosocial perspectives on caring for and contributing to the next generation (pp. 75-100). Washington, DC: APA. 
MEN IN MID-LATE CAREER

Sullivan, S. E., \& Baruch, Y. (2009). Advances in career theory and research: A critical review and agenda for future exploration. Journal of Management, 35, 1542-1571.

doi:10.1177/0149206309350082

Super, D. E., Savickas, M. L., \& Super, C. M. (1995). The life-span, life-space approach to careers. In D. Brown \& L. Brooks (Eds), Career choice and development. San Francisco: Jossey-Bass.

Super, D. E., Thompson, A. S., \& Lindeman, R. H. (1988). Adult career concerns inventory: Manual for research and exploratory use in counselling. Palo Alto, CA: Consulting Psychologists Press.

Truxillo, D. M., Cadiz, D. M., Rineer, J. R., Zaniboni, S., \& Fraccaroli, F. (2012). A lifespan perspective on job design: Fitting the job and the worker to promote job satisfaction, engagement, and performance. Organizational Psychology Review, 2, 340-360. doi:10.1177/2041386612454043

Warr, P., Miles, A., \& Platts, C. (2001). Age and personality in the British population between 16 and 64 years. Journal of Occupational and Organizational Psychology, 74, 165-199. doi:0.1348/096317901167307

Weigl, M., Müller, A., Hornung, S., Zacher, H., \& Angerer, P. (2013). The moderating effects of job control and selection, optimization, and compensation strategies on the age-work ability relationship. Journal of Organizational Behavior, 34, 607-628. doi:10.1002/job.1810

Westenberg, P. M. \& Block, J. (1993). Ego development and individual differences in personality. Journal of Personality and Social Psychology, 65, 792-800. doi:10.1037/0022-3514.65.4.792

Whitbourne, S. K. (1986). Openness to experience, identity flexibility, and life change in adults. Journal of Personality \& Social Psychology, 50, 163-168. doi: $\underline{10.1037 / 0022-3514.50 .1 .163}$ 
MEN IN MID-LATE CAREER

Wille, B., Beyers, W., \& De Fruyt, F. (2013). A transactional approach to person-environment fit: Reciprocal relations between personality development and career role growth across young to middle adulthood. Journal of Vocational Behavior, 81, 307-321. doi: 10.1016/j.jvb.2012.06.004

Woods, S. A., Lievens, F., De Fruyt, F., \& Wille, B. (2013). Personality across working life: The longitudinal and reciprocal influences of personality on work. Journal of Organizational Behavior, 34, S7-S25. doi: 10.1002/job.1863

Zacher, H., Rosing, K., Henning, T., \& Frese, M. (2011). Establishing the next generation at work: Leader generativity as a moderator of the relationships between leader age, leader-member exchange, and leadership success. Psychology and Aging, 26, 241-252. doi:10.1037/a0021429

Zacher, H., Schmitt, A., \& Gielnik, M. M. (2012). Stepping into my shoes: generativity as a mediator of the relationship between business owners' age and family succession. Ageing and Society, 32, 673-696. doi:10.1017/S0144686X11000547 
MEN IN MID/LATE CAREER

Table 1

Descriptive Statistics and Correlations of Key Variables Employed in the Study $(N=41)$

\begin{tabular}{|c|c|c|c|c|c|c|c|c|c|c|c|c|c|}
\hline $\begin{array}{l}3 \\
\text { 3. }\end{array}$ & $g$ & 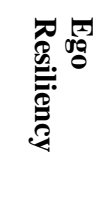 & 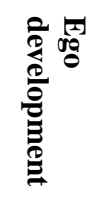 & 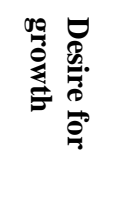 & 紫音 & 命 & 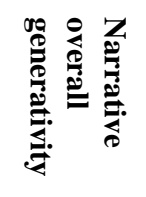 & 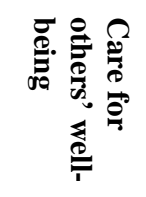 & 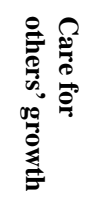 & 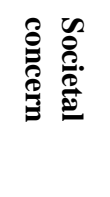 & 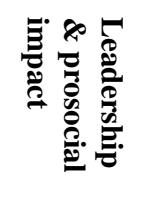 & 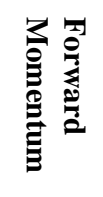 & 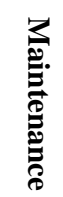 \\
\hline
\end{tabular}

\section{Personality}

\begin{tabular}{lcccccc} 
Ego resiliency & 77.29 & 13.94 & 1 & & \\
Ego development & 5.46 & 0.84 & -.03 & 1 & \\
Personal growth & & & & & \\
\hline Desire for growth & 9.83 & 3.38 & $.40^{*}$ & .15 & 1 & \\
Narrative growth & 5.10 & 3.70 & .16 & $.62^{* * *}$ & $.33^{*}$ & 1
\end{tabular}

\section{Generativity}

$\mathrm{LGS}^{\mathrm{a}}$

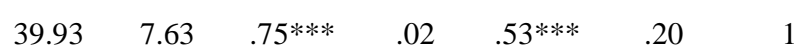

Narrative overall

generativity

$9.24 \quad 5.63$

$.44 * * \quad .16$

$.46 * * \quad .28 \dagger$

$.69 * * * \quad 1$

of which:

- Care for others'

well-being

$1.76 \quad 1.74$

- Care for others'

\section{growth}

$2.63 \quad 2$

- Societal concern

$2.44 \quad 1$.

- Leadership \&

prosocial impact

$2.41 \quad 1.76$

1.76


MEN IN MID-LATE CAREER

\section{Career orientation}

Forward momentum

$\begin{array}{llllllllllllllll}34.76 & 29.28 & .40^{* *} & .14 & .40^{* *} & .38^{*} & .37 * & .38^{*} & .14 & .32 * & .46^{* *} & .17 & 1 & \\ 42.44 & 30.99 & -.11 & -.14 & -.36^{*} & -.40^{* *} & -.17 & -.39 * & -.10 & -.31 \dagger & -.44^{* *} & -.29 \dagger & -.75^{* * *} & 1\end{array}$

Note: ${ }^{a}$ Loyola Generativity scale

$\dagger p<.10 \quad * p<.05 \quad * * p<.01 \quad * * * p<.001$ 
MEN IN MID-LATE CAREER

Table 2

Regressions of Generativity and Growth on Resiliency, Ego Development, and Career Orientation

\begin{tabular}{|c|c|c|c|c|}
\hline & $\begin{array}{l}\text { Desire for } \\
\text { growth }\end{array}$ & $\begin{array}{l}\text { Narrative } \\
\text { growth }\end{array}$ & $\begin{array}{c}\text { LGS } \\
\text { generativity }\end{array}$ & $\begin{array}{c}\text { Narrative } \\
\text { generativity }\end{array}$ \\
\hline \multicolumn{5}{|c|}{ Step 1: Ego resiliency and Ego development } \\
\hline$R^{2}\left(\right.$ Adjusted $\left.R^{2}\right)$ & $.18(.14)$ & $.42(.39)$ & $.56(.54)$ & $.22(.18)$ \\
\hline$F(2,38)$ & $4.27 *$ & $13.7 * * *$ & $26.6^{* * *}$ & $5.44^{* *}$ \\
\hline \multicolumn{5}{|c|}{ Standardized regression coefficients at Step 1} \\
\hline Ego resiliency & $.40 * *$ & .18 & $.75 * * *$ & $.44^{* *}$ \\
\hline Ego development & .17 & $.63 * * *$ & .04 & .18 \\
\hline \multicolumn{5}{|c|}{ Step 2: Forward momentum and Maintenance } \\
\hline$R^{2}$ (Adjusted $R^{2}$ ) for both steps & $.27(.19)$ & $.51(.45)$ & $.57(.52)$ & $.33(.25)$ \\
\hline$F(4,36)$ & $3.32 *$ & $9.26 * * *$ & $12.0 * * *$ & $4.39 * *$ \\
\hline$F$ for change in $R^{2}$ & 2.12 & $3.23 \dagger$ & 0.27 & $2.83 \dagger$ \\
\hline \multicolumn{5}{|c|}{ Standardized regression coefficients at step 2} \\
\hline Ego resiliency & $.35 *$ & .13 & $.74^{* * *}$ & $.45 * *$ \\
\hline Ego development & .12 & $.58 * * *$ & .03 & .14 \\
\hline Forward momentum & .04 & .04 & .02 & -.13 \\
\hline Maintenance & -.27 & -.27 & -.07 & $-.41 \dagger$ \\
\hline
\end{tabular}

$\dagger p<.10 \quad * p<.05 \quad * * p<.01 \quad * * * p<.001$

